This is an electronic reprint of the original article. This reprint may differ from the original in pagination and typographic detail.

Author(s): Rosso, Valeria; Gastaldi, L.; Rapp, W.; Lindinger, S.; Vanlandewijck, Y.; Linnamo, Vesa

Title: $\quad$ Biomechanics of simulated versus natural cross-country sit skiing

Year: $\quad 2017$

Version:

Please cite the original version:

Rosso, V., Gastaldi, L., Rapp, W., Lindinger, S., Vanlandewijck, Y., \& Linnamo, V. (2017). Biomechanics of simulated versus natural cross-country sit skiing. Journal of Electromyography and Kinesiology, 32, 15-21.

https://doi.org/10.1016/j.jelekin.2016.11.002

All material supplied via JYX is protected by copyright and other intellectual property rights, and duplication or sale of all or part of any of the repository collections is not permitted, except that material may be duplicated by you for your research use or educational purposes in electronic or print form. You must obtain permission for any other use. Electronic or print copies may not be offered, whether for sale or otherwise to anyone who is not an authorised user. 


\section{Accepted Manuscript}

Biomechanics of simulated versus natural cross-country sit skiing

V. Rosso, L. Gastaldi, W. Rapp, S. Lindinger, Y. Vanlandewijck, V. Linnamo

PII:

S1050-6411(16)30267-X

DOI:

http://dx.doi.org/10.1016/j.jelekin.2016.11.002

Reference:

JJEK 2031

To appear in: $\quad$ Journal of Electromyography and Kinesiology

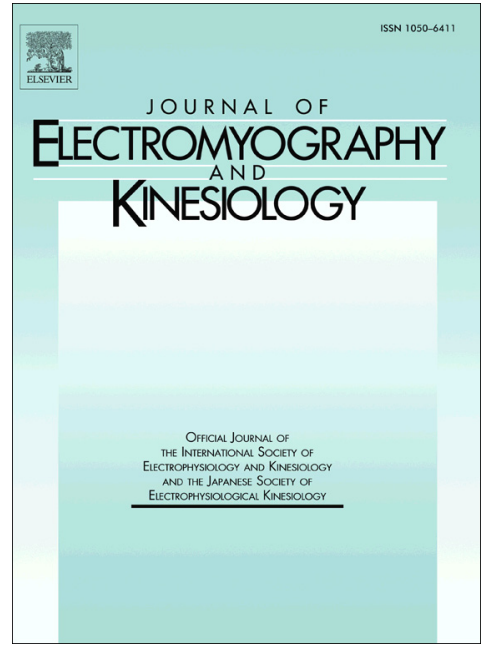

Received Date:

5 March 2016

Revised Date: $\quad 20$ September 2016

Accepted Date: $\quad 5$ November 2016

Please cite this article as: V. Rosso, L. Gastaldi, W. Rapp, S. Lindinger, Y. Vanlandewijck, V. Linnamo, Biomechanics of simulated versus natural cross-country sit skiing, Journal of Electromyography and Kinesiology (2016), doi: http://dx.doi.org/10.1016/j.jelekin.2016.11.002

This is a PDF file of an unedited manuscript that has been accepted for publication. As a service to our customers we are providing this early version of the manuscript. The manuscript will undergo copyediting, typesetting, and review of the resulting proof before it is published in its final form. Please note that during the production process errors may be discovered which could affect the content, and all legal disclaimers that apply to the journal pertain. 


\title{
Biomechanics of simulated versus natural cross-country sit skiing
}

\author{
Rosso $\mathrm{V}^{1,2}$, Gastaldi $\mathrm{L}^{1}$, Rapp $\mathrm{W}^{3}$, Lindinger $\mathrm{S}^{4}$, Vanlandewijck $\mathrm{Y}^{5}$, Linnamo $\mathrm{V}^{2}$ \\ ${ }^{1}$ Department of Mechanical and Aerospace Engineering, Politecnico di Torino, Italy \\ ${ }^{2}$ Department of Biology of Physical Activity, University of Jyväskylä, Finland \\ ${ }^{3}$ Departement of Sport and Sport Science, University of Freiburg, Germany \\ ${ }^{4}$ Department of Sport Science and Kinesiology, University of Salzburg, Austria \\ ${ }^{5}$ Department of Rehabilitation Sciences, KU Leuven, Belgium
}

Keywords: Paralympics; Impairment; Ergometer; EMG.

Corresponding author:

Valeria Rosso

Department of Mechanical and Aerospace Engineering, Politecnico di Torino

Corso Duca degli Abruzzi 24, Torino, Italy

Telephone: $+393339384868 /+39011.090 .6941$

E-mail: valeria_rosso@polito.it 


\section{Abstract}

The purpose of this study was to investigate the biomechanics of cross-country sit-skiing in simulated and natural skiing. Thirteen international level athletes participated in a ski ergometer test (simulated conditions) and a test on snow in a ski-tunnel (natural conditions) using their personal sit-ski. Tests in both conditions were performed at individual maximal speed. When comparing the two conditions the main results were: 1) maximal speed in simulated conditions was lower $(\mathrm{p}<0.05)$ but correlated well with the natural condition $(\mathrm{r}=0.79, \mathrm{p}<0.001) ; 2)$ no differences in pole force variables were found; peak force $(\mathrm{r}=0.77$, $\mathrm{p}<0.01)$ and average force $(\mathrm{r}=0.78, \mathrm{p}<0.01)$ correlated well; 3$)$ recovery time and time to peak did not differ and time to impact correlated with each other $(\mathrm{r}=0.88, \mathrm{p}<0.01) ; 4)$ no differences were found in peak electromyography (EMG) and average EMG for Triceps, Pectoralis, and Erector Spinae; Rectus Abdominis did not differ in peak. EMG peak and average EMG of all muscles were correlated between the two conditions ( $r=0.65-0.94$; $\mathrm{p}<0.05-0.01)$. Although some differences were observed, this study demonstrated that technical skill proficiency in natural and simulated cross-country skiing is comparable from a force production and muscle activation perspective. 


\section{Introduction}

Since the first Paralympic cross-country (XC) skiing event, the number of athletes who practice this discipline has grown markedly while live television broadcasting and print media attention have also increased (Rombach and Rapp 2014). Paralympic athletes with neuromusculoskeletal impairments are divided in two categories: standing and sitting. To ensure equal and fair competitions and to minimize the effects of impairment on performance within each category, athletes are divided into classes according to the impact of neuromusculoskeletal impairment on XC-skiing performance (Vanlandewijck 2006; Tweedy and Vanlandewijck 2011; International Paralympic Committee 2015). All sit-skiers have impairment in the lower limbs, but a different level of ability to control the trunk. Therefore, sit-skiers are grouped in five different classes LW (locomotor winter), from LW12 (athletes can perfectly control their trunk muscles) to LW10 (athletes with no voluntary abdominal and trunk extensor control), with three intermediate categories: LW11.5, LW11 and LW10.5 (International Paralympic Committee 2015). Independent of the impairment level, all sitskiers adopt the double poling (DP) technique for propulsion. DP is a technique in which athletes sitting on a sledge mounted on a couple of cross-country skis, sit-ski, generate propulsion by using shoulder and arm muscles to push on two poles synchronously; the propulsion is increased by a flexion-extension movement in the trunk.

Although many studies have been conducted on the physiology (Hoffmann et al. 1991; Pellegrini et al. 2013), biomechanics (Millet et al. 1998a, 1998b; Holmberg et al. 2005, 2006; Stöggl and Holmberg 2011; Zoppirolli et al. 2015), and neuromuscular activity (Holmberg et al. 2005) of able-bodied skiers in DP, very few studies have assessed this technique in sitskiing. Bernardi et al. (2013) evaluated changes in speed and kinematic parameters during flat and uphill tracks, finding an average cycle duration of $0.98 \mathrm{~s}$ and $0.84 \mathrm{~s}$ respectively, while Gastaldi et al. (2012, 2014, 2016), investigated DP kinematics in sit-skiing athletes belonging 
to different classes using a markerless kinematic analysis. In the comparison of DP technique of different classes (LW10 and LW11) it was demonstrated that athletes kneeling on the sitski (kneeing position) and athletes sitting on the sit-ski with the knees in a higher position relative to the hip joints (knee-high position) had significantly different trunk movement (Gastaldi et al. 2012). Finally, the trunk movement was assessed in simulated skiing among athletes with different impairments, demonstrating that athletes with a lower impairment level had a greater range of motion (ROM) and a more flexed trunk position during the DP cycle than athletes with a higher impairment level (Rosso et al. 2016).

Studies on DP sit-skiing (Gastaldi et al. 2012; Bernardi et al. 2013) showed that conducting tests skiing on snow (natural conditions) can be challenging in providing precise and comparable results due to the environmental constrictions; therefore it is necessary to introduce standardized test procedures for valid assessment and training. Such test procedures can be conducted in a laboratory, which guarantees standardization, easy access to the athlete, and less technological challenges. In able-bodied athletes laboratory tests on an ergometer (simulated conditions) have been conducted to evaluate if testing and training simulating DP technique gives accurate and valid results and comparable movements in terms of muscle recruitment and forces (Holmberg and Nilsson 2008; Halonen et al. 2014). Although Halonen et al. (2014) found a difference in abdominal muscle activation time between simulated and natural conditions, a strong correlation was found in power generation during a six-minute test (Holmberg and Nilsson 2008), in force production and muscle activities, and in impact of fatigue (Halonen et al. 2014). Comparison between simulated and natural conditions has also been done in XC sit-skiing. Forbes et al. (2010) compared aerobic response measuring cardiorespiratory variables, such as peak oxygen consumption $\left(\mathrm{VO}_{2 \text { peak }}\right)$, peak heart rate, peak respiratory exchange ratio, and anaerobic response measuring blood lactate. Forbes et al. (2010) reported no differences in $\mathrm{VO}_{2}$, but higher values in all other variables in simulated 
compared to natural conditions. Other studies have used simulated conditions to describe sitskiers' physical fitness and consequently give advice on training and performance (Bernardi et al. 2010, 2012; Bernardi and Schena 2011). An arm cranking ergometer was used to assess both aerobic and anaerobic responses showing high values for $\mathrm{VO}_{2 \text { peak }}$, heart rate, and blood lactate (Bernardi et al. 2010; Bernardi and Schena 2011), while upper body muscular strength was identified as a key factor for both aerobic and anaerobic capacity (Bernardi et ál. 2012). $\mathrm{VO}_{2 \text { peak }}$-values as a result of incremental maximal cardiopulmonary arm-cranking, present a close relationship with $\mathrm{VO}_{2}$ measured during a $5 \mathrm{~km}$ simulated race (Bernardi et al. 2010).

The aim of this paper is to compare force generation and muscle activity patterns in sitski athletes using an XC-ergometer versus natural conditions on snow. It would permit to consider if $\mathrm{XC}$-ergometer is a valid alternative for specific training, to improve $\mathrm{XC}$ sit-skiing performance in natural conditions.

\section{Methods}

\section{Participants}

Thirteen healthy elite Paralympic XC sit-skiers (8 male, members of seven different National teams; representing different classes LW10 n=1, LW10.5 n=1, LW11 n=3, LW11.5 n=4, LW12 n=4; age $27 \pm 3$ years (20-33), height $167 \pm 20 \mathrm{~cm}(110-192)$, weight $58 \pm 12 \mathrm{~kg}$ (3079)) volunteered as participants. Participants were informed in full detail about the aim and the nature of the study and they signed an informed consent. The research methods and the protocols were standard and have been approved by the Ethics Committee of the University of Jyväskylä and the measurements were performed in accordance with the Declaration of Helsinki.

Overall design and experimental setup 
All the tests were conducted during the International Paralympic Committee (IPC) World Cup in December 2014 in Vuokatti, Finland. The protocol consisted of two parts: the first part took place in a laboratory, while the second part was conducted in the Vuokatti Ski Tunnel.

The athlete was prepared for testing and practiced with the XC-ergometer (Concept2 Inc, Morrisville, Vermont, USA) for 5 to 10 minutes to warm up and to become familiar with the equipment. All the athletes used the same ergometer but with their own sit-ski. For each athlete, the sit-ski was fixed with respect to the ergometer at the distance that allowed the skier to have technique as similar as possible to the one usually used in natural condition. The $\mathrm{XC}$-ergometer (Figure 1) was fixed to the wall in a vertical position; this setup allowed the athletes to activate the flywheel by pulling the ropes using two handles. The ergometer resistance was set at 7.5 out of 10 (arbitrary units) for all participants; this level was chosen based on pilot tests to best simulate natural skiing conditions in the Vuokatti Ski Tunnel. Two maximal speed $\left(\operatorname{speed}_{\max }\right)$ trials were performed and separated by 2 minutes of recovery. The athletes were requested to execute at least 7 cycles after $\operatorname{speed}_{\max }$ was reached. As a consequence, each trial lasted no longer that $15 \mathrm{~s}$. The best trial at speed $\max _{\max }$ (characterized as the fastest) was selected and analyzed. The speed $_{\max }$ condition was chosen because of its importance in race strategies. It has been demonstrated (Bernardi et al. 2012) that in races sitskiers adopt the "all out" strategy in which athletes start with a high speed and that this subsequently decreases during the race.

For the second part of the experiment, the athlete was transferred to the Vuokatti Ski Tunnel (constant temperature of $-7^{\circ}$ and humidity condition). The sit-ski was the same used in the laboratory test (personal sit-ski) and poles equipped with force transducers were provided to skiers (lengths from $100-130 \mathrm{~cm}$ at $2.5 \mathrm{~cm}$ increments). The skis were prepared by the athletes' own ski service team before the measurements started. The track profile was chosen to be $16 \mathrm{~m}$ long at $2.5^{\circ}$ of slope and was also selected based on pilot tests. Two speed $_{\max }$ tests 
with a recovery of 2 min in between were performed; the fastest was selected for further analysis.

\section{Maximal speed}

In simulated conditions the maximal speed was calculated by using data recorded by the ergometer software. The ergometer gave a value, which is the time required to cover a distance of $500 \mathrm{~m}$ if the speed the athlete has in that moment will be maintained. The maximal speed was the ratio between the theoretical distance of $500 \mathrm{~m}$ and the time given by the ergometer. In natural conditions the speed was measured with radar (Jenoptik LDM $300 \mathrm{C}$ SPORT, Jena, Germany).

\section{Force and cycle characteristics measurements}

In simulated conditions, the ergometer was equipped with force transducers (University of Jyväskylä, Finland) mounted between the pulling rope and handle grip. Pulling forces were collected at $3000 \mathrm{~Hz}$ by Vicon Nexus software (Vicon Motion Systems Ltd. UK). In natural conditions poles were equipped with a strain gauge force transducer mounted directly in the pole grip (University of Salzburg, Austria). Force data were collected at $1000 \mathrm{~Hz}$ using a custom-made data collection system explained in a previous study (Halonen et al. 2014).

In Figure 2 cycle characteristics and poling forces are presented for both simulated and natural conditions. Cycle time (CT), poling time (PT), and recovery time (RT) were the duration of the DP cycle, poling phase (PP), and recovery phase (RP) respectively. The impact force (force impact$_{\text {) }}$ occurred at the impact of the pole to the ground and was characterized as the first force peak occurring during the PP; the peak force (force peak $_{\text {) is }}$ related to propulsion and was determined as the highest active peak force after the impact during the PP (Figure 2). The other force variables calculated were average force (force ${ }_{\text {avg }}$ ) and integral force (force int $_{\text {) }}$, while the cycle characteristics variables were time to impact (TtI) and time to peak (TtP). TtI and TtP were defined as the time between the beginning of the PP 
and the time when the force impact $_{\text {and force }}$ peak occurred, respectively. All biomechanical variables were calculated for each of seven consecutive propulsion cycles in the same manner in both simulated and natural conditions.

\section{Muscle activity measurements}

Muscle activity was acquired by a surface electromyographical system that transmitted the data wirelessly (TeleMyo DTS, Noraxon U.S.A. Inc, United States) to a personal computer and was stored by Vicon Nexus software. The TeleMyo DTS system is composed of sensors system, which include a small amplifier, and a belt transmitter, to transmit data from the sensors to a synchronization station and then to a personal computer by a USB connection. The system applied a pass-band filter $(20-400 \mathrm{~Hz})$ and converted analog signals to digital data by a 16-bit A/D converter. In simulated conditions signals were sampled at $3000 \mathrm{~Hz}$ and synchronized with force data. In natural conditions a sample frequency of $1500 \mathrm{~Hz}$ was used. Moreover, the Triceps (Tric) activity was registered at $1000 \mathrm{~Hz}$ by the custom-made system used to collect pole forces. This double acquisition was used to manually synchronize forces and muscle activity signals from the two acquisition systems.

Muscle activity signals were recorded in a single differential configuration using pre-gelled $\mathrm{Ag} / \mathrm{AgCl}$ bipolar surface electrodes (circle shape, sensor area $28 \mathrm{~mm}^{2}$ ) with an inter-electrode distance of $15 \mathrm{~mm}$ (Ambu BlueSensor N, Ambu A/S, Denmark). The electrodes were positioned according to SENIAM recommendation (Hermens et al. 2000) on the most prominent muscle belly in the line of the muscle fiber direction, and were placed over 8 muscles: Tric, Pectoralis Major (Pec), Latissimus Dorsi (Lat), Rectus Abdominis (RecAb), Obliquus Abdominis, Erector Spinae (ES), Rectus Femoris and Biceps Femoris muscles of the right side of the body. A reference electrode was placed on the right acromion. Before electrode positioning, the skin was abraded and cleaned with alcohol. Since for the majority of the participants the activity of Obliquus Abdominis, Rectus Femoris and Biceps Femoris 
was low, these muscles were not taken into account in final analysis. The low activation was justified by the individuals' impairment and their lack in trunk and lower limb muscle control.

Raw muscle activity signals were full-wave rectified and $10 \mathrm{~Hz}$ low pass filtered to create a linear envelope. For each cycle the average muscle activity (aEMG) and the muscle activity peak $\left(\mathrm{EMG}_{\text {peak }}\right)$ were calculated on the rectified signals and on the linear envelope respectively (Holmberg et al. 2005). Since the minimum number of good cycles available for all the athletes was lower than seven, neuromuscular variables were calculated from five out of seven consecutive propulsion cycles. To analyze coordination patterns, an electromechanical delay was evaluated as a difference between two time instances. During each PP both muscle activity and force signals increased from and then decreased to a baseline value. The muscle activity and force onset corresponded to the time instant when increasing signals reached $10 \%$ of their maximum. The difference between muscle activity onset and force onset is generally defined as onset delay. The offset delay was calculated in the same way when the muscle activity and force signals decreased. The onset and offset delay was reported negative when the muscle activation occurred before the force, both in terms of activation and deactivation. A ratio between natural and simulated conditions for muscle activity variables has been calculated to compare muscle activation levels in different conditions (Pellegrini et al. 2005).

The force, cycle characteristics, and neuromuscular data were processed using custommade code prepared in MatLab (MatLab and Release 2015, The MathWorks, Inc., Natick, Massachusetts, United States).

\section{Statistics}

Since the data did not show a normal distribution (Kolmogorov-Smirnov test; $\mathrm{p}<0.01$ ) nonparametric statistics was applied. Data was presented as mean and standard deviation and median \pm interquartile range (IQR) in the tables. To check for statistical differences between 
the two conditions, a Wilcoxon test was applied and a pairwise comparison using Spearman correlation coefficient (r) was calculated for each variable. Statistical significance was set at $\mathrm{p}<0.05$ for all analyses. All statistical analyses were processed using MatLab.

\section{Results}

Speed $_{\max }$ values, forces and cycle characteristics in natural and simulated conditions were reported as mean $\pm \mathrm{SD}$ and median $\pm \mathrm{IQR}$ in table 1. Speed $_{\max }$ in natural conditions was higher $(\mathrm{p}<0.05)$ than in simulated conditions. A positive significant correlation was found between simulated and natural skiing $(r=0.79, \mathrm{p}<0.001)$.

No differences were found between simulated and natural conditions in the force impact, $_{\text {, }}$ force $_{\text {peak }}$, force $e_{\text {avg }}, \mathrm{RT}$, and TtP. In contrast, in simulated conditions the force $\mathrm{ent}_{\text {int }}(\mathrm{p}<0.001)$, the CT $(\mathrm{p}<0.001)$, the PT $(\mathrm{p}<0.001)$, and the TtI $(\mathrm{p}<0,01)$ were higher compared to the natural conditions. A positive significant correlation was found between simulated and natural conditions in force peak $_{(}(\mathrm{r}=0.77, \mathrm{p}<0.01)$, force ${ }_{a v g}(\mathrm{r}=0.78, \mathrm{p}<0.01)$, and TtI $(r=0.88, \mathrm{p}<0.01)$.

Muscle activation values were reported as mean $\pm \mathrm{SD}$ and median $\pm \mathrm{IQR}$ of the ratio natural/simulated in the table 2 , while muscle activation onset and offset delay in the two conditions were reported as mean $\pm \mathrm{SD}$ in figure 3 .

Concerning the muscle activation, no differences were found between simulated and natural conditions in the $\mathrm{EMG}_{\text {peak }}$ and aEMG for Tric, Pec, ES, and in $\mathrm{EMG}_{\text {peak }}$ for RecAb. In contrast, higher activation was found in simulated compared to natural conditions in $\mathrm{EMG}_{\text {peak }}$ for Lat $(\mathrm{p}<0.05)$, in aEMG for Lat $(\mathrm{p}<0.05)$ and $\operatorname{RecAb}(\mathrm{p}<0.05)$. Concerning the onset delay (Figure 3A), Tric $(\mathrm{p}<0.001)$, Pec $(\mathrm{p}<0.001)$, Lat $(\mathrm{p}<0.001)$, and ES $(\mathrm{p}<0.05)$ were activated later in simulated than in natural conditions. Regarding the offset time (Figure 3B), Tric $(\mathrm{p}<0.05)$ and Lat $(\mathrm{p}<0.01)$ were deactivated later in simulated than in natural conditions.

A positive significant correlation was found between simulated and natural conditions for all muscles in $\mathrm{EMG}_{\text {peak }}$ Tric $(\mathrm{r}=0.69, \mathrm{p}<0.01), \operatorname{Pec}(\mathrm{r}=0.88, \mathrm{p}<0.01)$, Lat $(\mathrm{r}=0.94, \mathrm{p}<0.01)$, ES 
$(\mathrm{r}=0.77, \mathrm{p}<0.05), \operatorname{RecAb}(\mathrm{r}=0.78, \mathrm{p}<0.01)$ and aEMG Tric $(\mathrm{r}=0.69, \mathrm{p}<0.05), \operatorname{Pec}(\mathrm{r}=0.77$, $\mathrm{p}<0.01)$, Lat $(\mathrm{r}=0.80, \mathrm{p}<0.01), \operatorname{ES}(\mathrm{r}=0.65, \mathrm{p}<0.05), \operatorname{Rec} \mathrm{Ab}(\mathrm{r}=0.75, \mathrm{p}<0.01)$.

\section{Discussion}

The present study aimed to compare force generation, cycle characteristics, and muscular activity of XC sit-skiers during simulated and natural conditions and showed that activity patterns of the major trunk and arm muscles during simulated $\mathrm{XC}$-skiing on an ergometer mirrored natural XC-skiing well.

Comparing the two conditions, maximal speed was significantly lower using the ski ergometer than in the tunnel. Nevertheless, the positive correlation found between the two conditions means that athletes skiing faster on the snow were able to obtain better performances also in simulated conditions. Mean speed values obtained in the current study in natural conditions are higher compared to the speed measured during the first lap of a race in a previous study (Bernardi et al. 2013); a lower slope $\left(2.5^{\circ}\right.$ vs $\left.8.3^{\circ}\right)$ and a shorter time of effort in the present study might explain these differences.

Force is generated differently in simulated conditions (traction force) and natural conditions (pushing force), thus comparing the muscle activity pattern and the biomechanical responses in both conditions may be influenced. A large treadmill would probably be closer to natural skiing than a simulation on the ski ergometer, but a ski ergometer is more accessible for many athletes to be used in training. One fundamental question of the present study was to compare generated forces in these two conditions and, despite the obvious differences, the forces measured were quite similar. If the main aim was to compare joint kinematics, a treadmill would have been preferred.

Forces generated showed two peaks per each DP cycle (Figure 2). The first peak occurred at the impact, while the second is related to propulsion. Compared to able-bodied athletes who showed lower impact force with respect to peak force (Holmberg et al. 2005), 
XC sit-skiers impact force was higher in both conditions. This higher impact force may be due to the sitting position and the ability of the athlete to take advantage of the force of gravity when poling, which influences the inclination of the pole at ground contact and subsequently the force transmitted to the ground at the impact through each pole. However, to verify this assumption, the direction of the force application should be measured. The impact force induced a pre-activation of Pectoralis and Rectus Abdominis (Figure 3A) to increase the muscle stiffness in order to prepare the body for the pole impact, and stabilizes the involved joints to generate more propulsion at the beginning of the poling phase similar to able-bodied skiers (Holmberg et al. 2005).

At maximal speed, the cycle time and the poling time were longer for athletes skiing in simulated conditions compared to natural conditions, while the recovery time was similar between the two conditions, which is in agreement with previous studies in able-bodied skiers (Pellegrini et al. 2005; Halonen et al. 2014). Moreover, the longer poling time leading to higher integral force during the poling phase is in line with a previous study conducted in able-bodied skiers as well (Halonen et al. 2014). The difference in the cycle time and poling time might be due to the higher resistance in simulated conditions indicated by lower speed and/or to different kinematics of the upper arms (traction force), which might lead to a greater elbow and shoulder range of motion during the poling phase. More specifically, it could be that in the simulated conditions at the end of the recovery phase athletes' wrists are in a more elevated position and the elbow joint angles are more extended than in natural conditions because of the elastic return force generated by the elastic mechanism inside the flywheel bringing the arms forward during the recovery phase. As a result, the first part of elbow flexion in the propulsion phase might be similar to a pull-up movement (Stöggl et al. 2006). This greater range of motion in the upper limbs could also explain the higher peak and average muscle activity for Latissimus during the poling phases in simulated compared to the 
natural conditions because of its extensor function in the first part of the poling phase (Holmberg et al. 2005). Moreover, a greater trunk flexion in simulated conditions during the poling phase could explain the higher Rectus Abdominis activation, which indicates better stability.

Concerning the onset and offset delay the high variability shown especially in abdominal muscles (Rectus Abdominis and Erector Spinae) can be due to the different classes of athletes included in this study. The decision to consider all the classes in the current sit-ski classification in the present study was because of the possibility to extend results to all sitskiers and the low number of athletes per each class. Statistical analysis on onset delay revealed later activation for Triceps, Pectoralis, Latissimus, and Erector Spinae in simulated compared to natural conditions. This could be due to the advantage in raising the upper limbs that athletes get from the elastic return force generated by the ergometer's flywheel during the recovery phase, while in natural conditions skiers must raise their upper limbs voluntarily. In contrast, the lack in difference for Rectus Abdominis onset delay is in contrast with the behavior showed by able-bodied athletes activating the Rectus Abdominis $0.1 \mathrm{~s}$ earlier using the ergometer compared to skiing on snow (Halonen et al. 2014). Despite this difference in activation time, the upper limb extensor muscle activation order is similar between simulated and natural conditions. This similarity suggests that in both conditions the gesture involves first a push (Triceps and Pectoralis) and then a pull (Latissimus and Erector Spinae) action, even though skiing on the ergometer athletes pull a rope while skiing on snow they push a couple of poles (Figure 3A). The offset delay showed a later deactivation of Triceps and Latissimus in simulated compared to natural conditions, which could be explained by the supposed greater upper limbs range of motion during the poling phase.

Despite these differences in Latissimus and Rectus Abdominis activity and the longer cycle and poling time, high correlations were found in the peak and average values of muscle 
activity for all muscles, in time to impact, peak force, and average force. These high correlations suggest that on the XC ergometer athletes who had higher absolute muscle activity and generated force in simulated conditions reacted the similarly in natural conditions.

To sum up, similar muscular activity in Triceps, Latissimus, and Erector Spinae muscles, activation pattern for Triceps, Pectoralis, Latissimus, Erector Spinae, and Rectus Abdominis muscles, and level of force generated were observed between natural and simulated conditions, while simulated condition had longer poling and cycle time and higher integral force. This comparable muscular activity, together with the similar pattern of activation and generated force in natural and simulated conditions suggest that the $\mathrm{XC}$ ergometer is a good device for training specific upper body maximal strength and testing aerobic and anaerobic capacity in sport-specific reliable and repeatable conditions. In contrast it might be that endurance training has negative effect on the technique due to the different upper limbs and trunk kinematics (Stöggl et al. 2006), but additional study focusing on motion analysis should be done.

\section{Limitations}

In the present study there are three main limitations. The first limitation is the small sample size. It would be important to get a representative number of athletes from each class, but this is difficult due to the low number of elite athletes competing in XC-sit skiing. The second is the lack of a kinematic analysis to evaluate trunk and upper limb angles and ROM, which allow only speculation regarding the possible explanations for the statistical differences found in time variables and muscle activation. The third is the lack of analysis in force directions that compared to sit-ski kinematics could give a reasonable explanation for the differences between standing able-bodied and sit-skiers in the impact force and peak force values and for 
the opposite order of activation in shoulder extensors. Indeed, athletes with strong trunk impairment try to compensate by changing their DP technique.

\section{Acknowledgements}

The authors are grateful to Magdalena Karczewska, Anna Madej, Marie Ohlsson, Xinyi Ji, Olli Ohtonen and the technical staff of the University of Jyväskylä, athletes for participating, Fondazione CRT VivoMeglio project, Finnish Ministry of Education and Culture and IPC for approving this research and for financial support. The authors report no conflict of interest.

\section{References}

Bernardi M, Carucci S, Faiola F, Egidi F, Marini C, Castellano V, et al. Physical Fitness Evaluation of Paralympic Winter Sports Sitting Athletes. Clin J Sport Med. 2012;22(2):26-30.

Bernardi M, Guerra E, Di Giacinto B, Di Cesare A, Castellano V, Bhambhani Y. Field evaluation of paralympic athletes in selected sports: Implications for training. Med Sci Sports Exerc. 2010;42(6):1200-8.

Bernardi M, Janssen T, Bortolan L, Pellegrini B, Fischer G, Schena F. Kinematics of crosscountry sit skiing during a Paralympic race. J Electromyogr Kinesiol. 2013;23(1):94101.

Bernardi M, Schena F. Preparation for the paralympic winter games: cold, altitude. In: Vanlandewijck Y, Thompson WR, editors. Handb Sport Med Sci paralympic Athl. Wiley-Blackwell; 2011. p. 231-48.

Forbes SC, Chilibeck PD, Craven B, Bhambhani Y. Comparison of a double poling ergometer and field test for elite cross country sit skiers. North Am J Sport Phys Ther. $2010 ; 5(2): 40-6$.

Gastaldi L, Lisco G, Pastorelli S. Inertial force assessment in cross-country sit-skiers. In: 
Müller E, Kröll J, Lindinger SJ, Pfusterschmied J, Stöggl T, editors. Sci Ski VI. Meyer and Meyer Sport; 2014. p. 377-86.

Gastaldi L, Mauro S, Pastorelli S. Analysis of the pushing phase in Paralympic cross-country sit-skiers - Class LW10. J Adv Res. 2016;7(6):971-8.

Gastaldi L, Pastorelli S, Frassinelli S. A Biomechanical Approach to Paralympic CrossCountry Sit-Ski Racing. Clin J Sport Med. 2012;22(1):58-64.

Halonen J, Ohtonen O, Lemmettylä T, Lindinger S, Rapp W, Häkkinen K, et al.

Biomechanics of double poling when skiing on snow and using an ergometer. In: Müller E, Kröll J, Lindinger S, Pfusterschmied J, Stöggl T, editors. Sci Ski VI. Meyer and Meyer Sport; 2014. p. 387-95.

Hermens HJ, Freriks B, Disselhorst-Klug C, Rau G. Development of recommendations for SEMG sensors and sensor placement procedures. J Electromyogr Kinesiol. 2000;10(5):361-74.

Hoffmann MD, Clifford PS, Jones GM, Bota B, Mandli M. Effects of technique and pole grip on physiological demands of roller skiing on level terrain. Int J Sports Med. $1991 ; 12(5): 468-73$.

Holmberg H, Lindinger S, Stöggl T, Björklund G, Müller E. Contribution of the legs to double-poling performance in elite cross-country skiers. Med Sci Sports Exerc. 2006;38(10):1853-60.

Holmberg H, Lindinger S, Stöggl T, Eitzlmair E, Müller E. Biomechanical analysis of double poling in elite cross-country skiers. Med Sci Sports Exerc. 2005;37(5):807-18.

Holmberg H, Nilsson J. Reliability and validity of a new double poling ergometer for crosscountry skiers. J Sports Sci. 2008;26(2):171-9.

International Paralympic Committee. International standard for Classification Data Protection 
[Internet]. 2015. Available from:

http://www.paralympic.org/sites/default/files/document/150813211735334_2015_07_07

+International+Standard+for+Classification+Data+Protection_FINAL_0.pdf

Millet G, Hoffman M, Candau R, Clifford P. Poling forces during roller skiing: effects of grade. Med Sci Sport Exerc. 1998a;30(11):1637-44.

Millet G, Hoffman M, Candau R, Clifford P. Poling forces during roller skiing: effects of technique and speed. Med Sci Sports Exerc. 1998b;30(11):1645-53.

Pellegrini B, Bortolan L, Zory R, Rouard A, Schena F. EMG evaluation of reproducibility of upper body motion of cross country ski on a custom-built ergometer. In: Dikic N, Zivanic S, Ostojic S, Tornjanski Z, editors. 10th Annu Congr Eur Coll Sport Sci. Belgrade; 2005. p. 38-3.

Pellegrini B, Zoppirolli C, Bortolan L, Holmberg H, Zamparo P, Schena F. Biomechanical and energetic determinants of technique selection in classical cross-country skiing. Hum Mov Sci. 2013;32(6):1415-29.

Rombach R, Rapp W. Analysis of support structures in Paralympic Nordic Skiing in interantional comparison - an exploratory study. In: Müller E, Kröll J, Lindinger SJ, Pfusterschmied J, Stöggl T, editors. Sci Ski VI. 6th ed. Meyer and Meyer sport; 2014. p. $465-74$

Rosso V, Linnamo V, Rapp W, Lindinger S, Vanlandewijck Y, Gastaldi L. Trunk kinematics during cross country sit-skiing ergometry. 2016 IEEE Int Symp Med Meas Appl. 2016.

Stöggl T, Holmberg H. Force interaction and 3D pole movement in double poling. Scand J Med Sci Sport. 2011;21(6):e393-404.

Stöggl T, Lindinger S, Müller E. Biomechanical validation of a specific upper body training and testing drill in cross-country skiing. Sports Biomech. 2006;5(1):23-46. 
Tweedy S, Vanlandewijck Y. International Paralympic Committee position stand-background and scientific principles of classification in Paralympic sport. Br J Sports Med. 2011;45(4):259-69.

Vanlandewijck Y. Sport science in the Paralympic movement. J Rehabil Res Dev. $2006 ; 43: 17-24$.

Zoppirolli C, Pellegrini B, Bortolan L, Schena F. Energetics and biomechanics of double poling in regional and high-level cross-country skiers. Eur J Appl Physiol. 2015;115(15):969-79. 


\section{Figure caption:}

Figure 1. Laboratory setup used for simulated skiing. A XC-ergometer allowed athletes to simulate the skiing gesture by means of a mechanical system of ropes and pulleys. A force transducer is inserted between each rope-handle grip coupling to collect force data and to evaluate cycle characteristics. Athletes performed the simulated skiing using their personal sit-ski and skies. The sit-ski was fixed with respect to the XC-ergometer at an adequate distance to allow the athletes to better simulate the gesture they demonstrated during natural skiing.

Figure 2. Force and cycle characteristics in the two conditions. A. This figure shows two of the force variables, impact force (force impact $_{\text {) and peak force (force }}$ peak), and three cycle characteristics variables, cycle time $(\mathrm{CT})$, poling time $(\mathrm{PT})$, and recovery time (RT), for simulated conditions. The force impact $_{\text {was }}$ characterized as the first force peak which occurred during the poling phase, while the force $e_{\text {peak }}$ was determined as the highest active peak force after the impact during the poling phase. The CT measured the double poling duration in seconds; the PT was the period of time which began when the force started to grow sharply with respect to the baseline value and ended when the force came down to the initial value; the RT was the mathematical difference between the CT and PT. B. The same force and cycle characteristics are shown in natural.

Figure 3. Onset and offset delay. The figure reported onset delay (Figure 3A) and offset delay (Figure 3B) for the five muscles (Tric, Pec, Lat, ES, RecAb) as mean \pm SD. This delay is calculated considering a threshold of $10 \%$ of the muscular activity and force peak. Statistical difference between the two conditions are reported, $*=\mathrm{p}<0.05, * *=\mathrm{p}<0.01, * * *=$ $\mathrm{p}<0.001$. 


\section{Acronym list}

$\mathrm{CT}=$ cycle time

$\mathrm{EMG}=$ electromyography

$\mathrm{aEMG}=$ average muscle activity

$\mathrm{EMG}_{\text {peak }}=$ muscle activity peak

$\mathrm{ES}=$ Erector Spinae muscle

$\mathrm{DP}=$ double poling

force $_{\mathrm{avg}}=$ average force during poling phase

force $_{\text {impact }}=$ force at the impact

force $_{\text {peak }}=$ peak of force in the poling phase

force $_{i n t}=$ integral of force during poling phase

IPC = International Paralympic Committee

$\mathrm{IQR}=$ interquartile range

Lat $=$ Latissimus Dorsi muscle

$\mathrm{LW}=$ locomotor winter

Pec $=$ Pectoralis Major muscle

$\mathrm{PP}=$ poling phase

$\mathrm{PT}=$ poling time

$\mathrm{RP}=$ recovery phase

$\mathrm{RT}=$ recovery time

$\mathrm{SD}=$ standard deviation

Speed $_{\max }=$ maximal speed

$\mathrm{TtP}=$ time to peak

$\mathrm{TtI}=$ time to impact

Tric $=$ Triceps Brachii muscle

$\operatorname{Rec} \mathrm{Ab}=$ Rectus Abdominis muscle

$\mathrm{VO}_{2}=$ oxygen consumption 
$\mathrm{XC}=$ cross-country

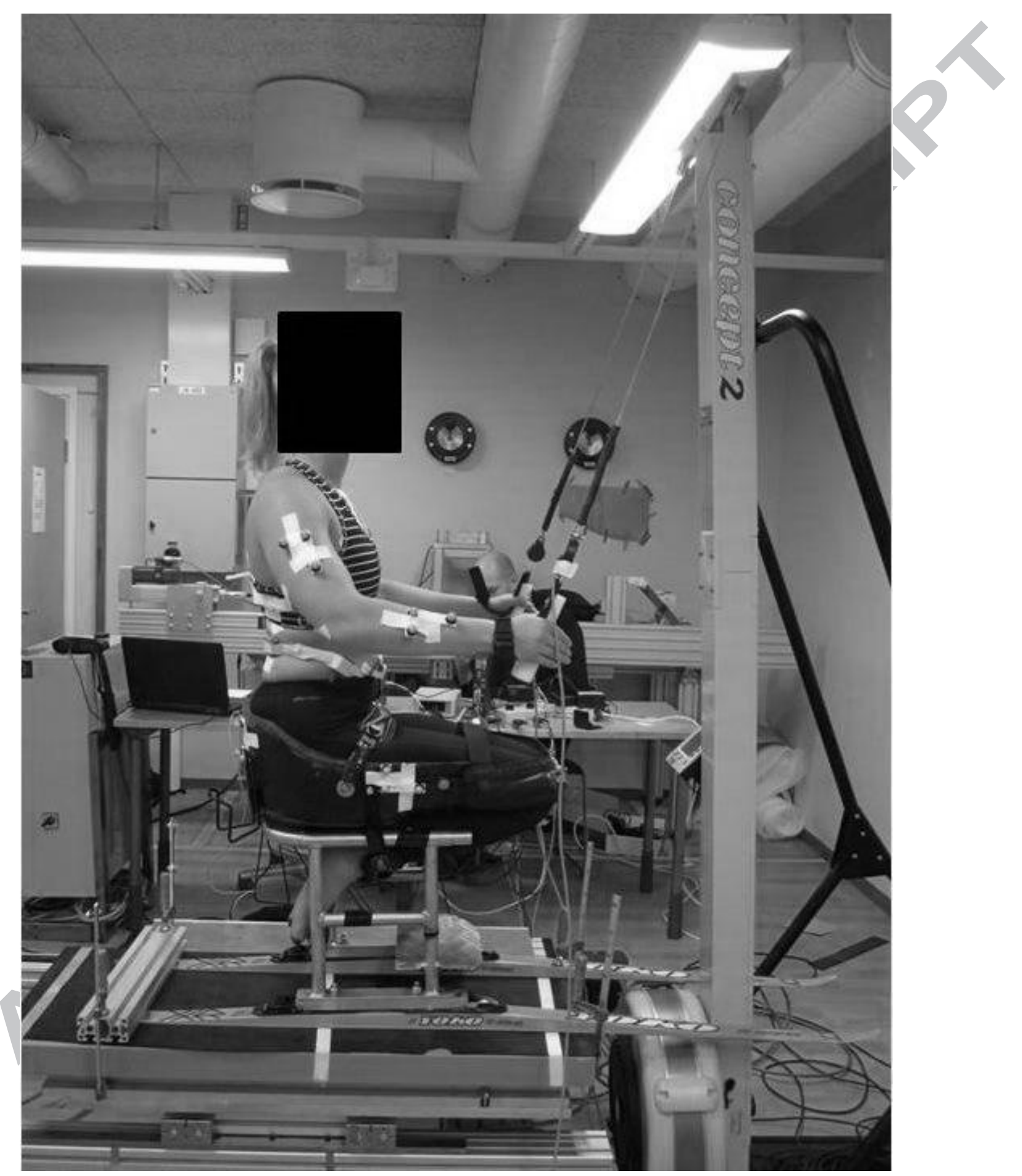




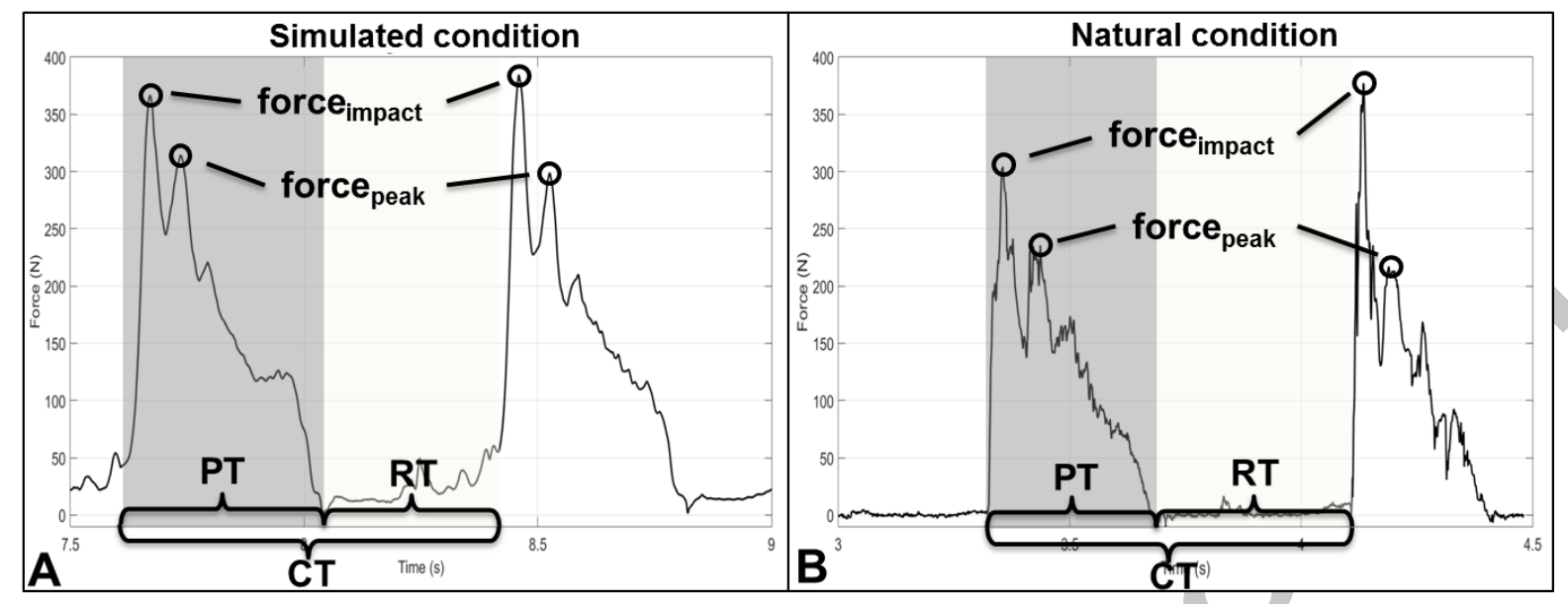



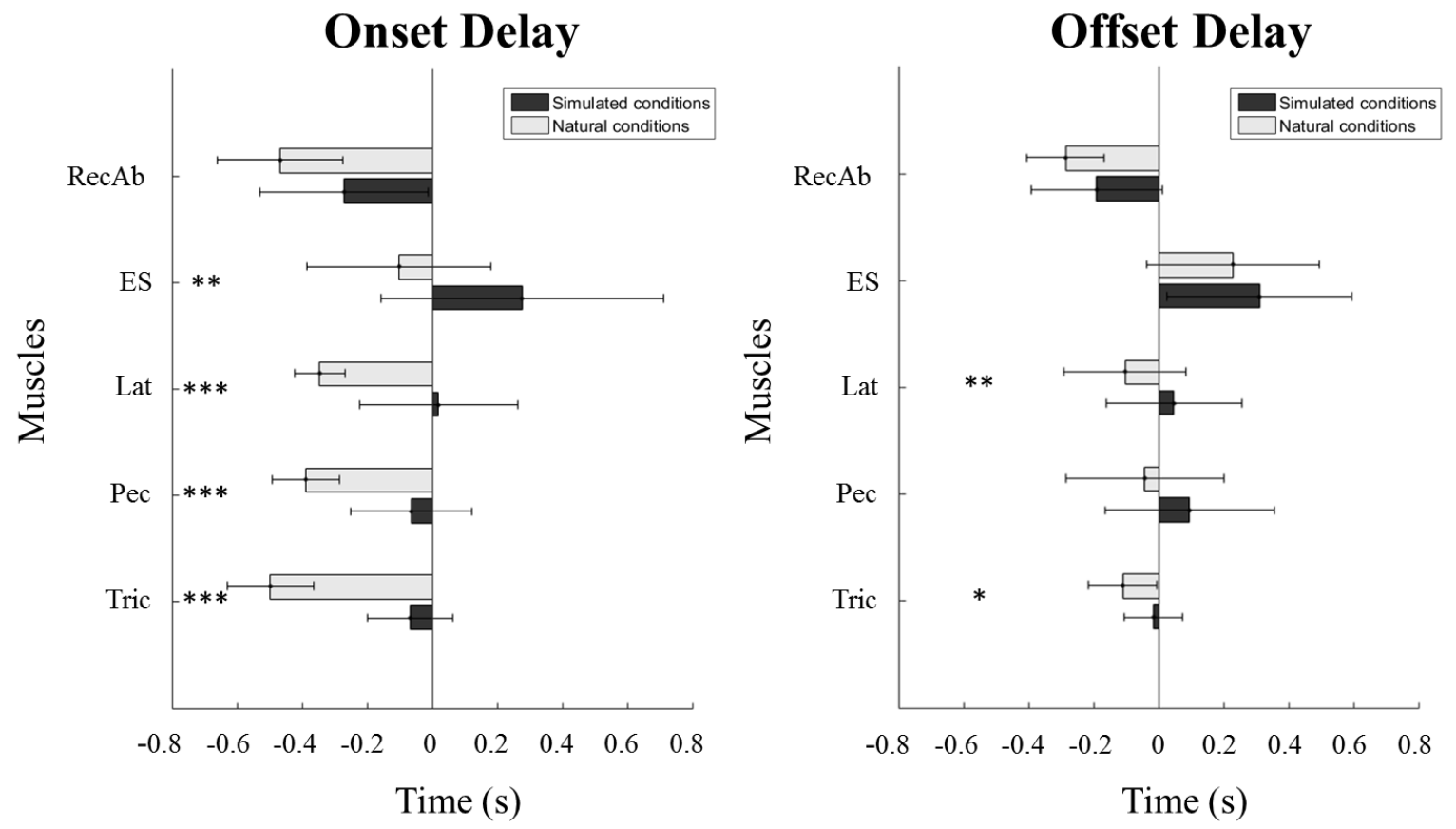


\begin{tabular}{|c|c|c|c|c|}
\hline Variable & $\begin{array}{l}\text { simulated conditions } \\
\text { mean } \pm \mathrm{SD}\end{array}$ & $\begin{array}{l}\text { natural conditions } \\
\text { mean } \pm \mathrm{SD}\end{array}$ & $\begin{array}{c}\text { simulated conditions } \\
\text { median } \pm \text { IQR }\end{array}$ & $\begin{array}{l}\text { natural conditions } \\
\text { median } \pm \mathrm{IQR}\end{array}$ \\
\hline $\operatorname{speed}_{\max }(\mathrm{m} / \mathrm{s})$ & $4.28 \pm 0.63 *$ & $4.61 \pm 0.67 *$ & $4.42 \pm 0.94^{*}$ & $4.68 \pm 1.16^{*}$ \\
\hline force $_{\text {impact }}(\mathrm{N})$ & $254.73 \pm 87.65$ & $257.95 \pm 94.02$ & $225.89 \pm 125.33$ & $256.23 \pm 86.28$ \\
\hline force $_{\text {peak }}(\mathrm{N})$ & $208.37 \pm 75.33$ & $188.55 \pm 54.58$ & $166.85 \pm 104.05$ & $169.18 \pm 62.53$ \\
\hline force $_{\text {avg }}(\mathrm{N})$ & $122.17 \pm 33.48$ & $114.28 \pm 28.36$ & $116.98 \pm 53.90$ & $123.68 \pm 33.89$ \\
\hline force $_{\text {int }}(\mathrm{Ns})$ & $59.91 \pm 16.60 * * *$ & $34.61 \pm 9.12 * * *$ & $54.74 \pm 17.25 * * *$ & $33.14 \pm 15.05 * * *$ \\
\hline $\mathrm{CT}(\mathrm{s})$ & $0.89 \pm 0.15^{* * *}$ & $0.66 \pm 0.11 * * *$ & $0.93 \pm 0.20 * * *$ & $0.62 \pm 0.19 * * *$ \\
\hline $\mathrm{PT}(\mathrm{s})$ & $0.47 \pm 0.08 * * *$ & $0.30 \pm 0.04 * * *$ & $0.46 \pm 0.14 * * *$ & $0.30 \pm 0.07 * * *$ \\
\hline RT (s) & $0.42 \pm 0.08$ & $0.36 \pm 0.08$ & $0.43 \pm 0.12$ & $0.32 \pm 0.15$ \\
\hline $\mathrm{TtP}(\mathrm{s})$ & $0.11 \pm 0.02$ & $0.10 \pm 0.03$ & $0.10 \pm 0.03$ & $0.09 \pm 0.05$ \\
\hline $\mathrm{TtI}(\mathrm{s})$ & $0.04 \pm 0.01 * *$ & $0.03 \pm 0.01 * *$ & $0.04 \pm 0.01 * *$ & $0.03 \pm 0.03 * *$ \\
\hline
\end{tabular}

Table 1. Maximal speed, force, and cycle characteristic values in the two conditions (simulated and natural) were reported as a mean \pm SD and median $\pm I Q R$. These values were obtained averaging five cycles per each subject. The statistical differences between the two conditions were reported, $*=\mathrm{p}<0.05, * *=\mathrm{p}<0.01, * * *=\mathrm{p}<0.001$.

$\operatorname{Speed}_{\max }(\mathrm{m} / \mathrm{s})$, maximal speed; force impact $(\mathrm{N})$, force at the impact; force peak $(\mathrm{N})$, peak force in the poling phase; aforce $(\mathrm{N})$, average force during poling phase; iforce $(\mathrm{N})$, integral force during poling phase; CT (s), cycle time; PT (s), poling time; RT (s), recovery time; TtP (s), time to peak; TtI (s), time to impact. 


\begin{tabular}{|c|c|c|c|}
\hline Variable & Muscle & $\begin{array}{l}\text { natural/simulated conditions } \\
\text { mean } \pm \mathrm{SD}\end{array}$ & $\begin{array}{c}\text { natural/simulated conditions } \\
\text { median } \pm \mathrm{IQR}\end{array}$ \\
\hline \multirow{5}{*}{$\mathrm{EMG}_{\text {peak }}$ (ratio) } & Tric & $1.07 \pm 0.48$ & $0.95 \pm 0.38$ \\
\hline & Pec & $1.11 \pm 0.50$ & $0.97 \pm 0.50$ \\
\hline & Lat & $0.85 \pm 0.19 *$ & $0.88 \pm 0.33 *$ \\
\hline & $\mathrm{ES}$ & $1.12 \pm 0.26$ & $1.11 \pm 0.25$ \\
\hline & $\mathrm{RecAb}$ & $0.95 \pm 0.34$ & $0.93 \pm 0.44$ \\
\hline \multirow{5}{*}{ aEMG (ratio) } & Tric & $0.94 \pm 0.39$ & $0.92 \pm 0.39$ \\
\hline & Pec & $0.96 \pm 0.46$ & $0.86 \pm 0.60$ \\
\hline & Lat & $0.80 \pm 0.22 *$ & $0.81 \pm 0.44 *$ \\
\hline & $\mathrm{ES}$ & $1.40 \pm 0.53$ & $1.27 \pm 0.99$ \\
\hline & $\mathrm{Rec} \mathrm{Ab}$ & $0.73 \pm 0.35^{*}$ & $0.73 \pm 0.39 *$ \\
\hline
\end{tabular}

Table 2. Muscular activation values in the two conditions (simulated and natural) were reported as a mean \pm SD and median $\pm \mathrm{IQR}$. These values were obtained averaging the same five cycles per each subject used for the force and cycle characteristics estimation. The statistical differences between the two conditions were reported, $*=p<0.05$.

$\mathrm{EMG}_{\text {peak }}$ (ratio), ratio between natural and simulated values of the muscle activity peak; aEMG (ratio), ratio between natural and simulated values of the average muscle activity; Tric, Triceps Brachii muscle; Pec, Pectoralis Major muscle; Lat, Latissimus Dorsi muscle; ES, Erector Spinae muscle; RecAb, Rectus Abdominis muscle. 


\section{Valeria Rosso:}

Valeria Rosso received her Master degree in Biomedical Engineering at the Politecnico di Torino, Italy in 2011. She is currently a Ph.D. candidate at the Department of Mechanical and Aerospace Engineering, Politecnico di Torino (Italy) and at the Department of Biology of Physical Activity, Faculty of Sport and Health Sciences, University of Jyväskylä (Finland). Her research interests involve biomechanics and motor control in cross country sit skiing.

\section{Laura Gastaldi:}

Laura graduated in Mechanical Engineering at the Politecnico di Torino and she received her PHD title in Applied Mechanics from the Politecnico di Torino in 1997.

She is assistant professor in Applied Mechanics and she is a lecturer of Machine Dynamics. Laura Gastaldi research activity is related to the study of mechanical, actuation and biomedical systems functional behaviour. In particular her most significant activities focused on modelling of physiological systems, biomechanics and man-machine interfaces.

\section{Walter Rapp:}

Walter Rapp graduated in Sport Science at University Stuttgart, Germany in 2000. He is working as researcher in the field of Biomechanics and Motor Control at Department of Sport and Sport Scincesat University of Freiburg. Walter Rapp is researching in the field of sport with disabled athletes. Special focus of his work is in Nordic Skiing and in Mountain biking.

\section{Stefan J Lindinger:}

Stefan $\mathbf{J}$ Lindinger graduated in Sport Science with specification in Biomechanics and Training at the University of Innsbruck, Austria and received his $\mathrm{PhD}$ at the University of Salzburg in the field of cross-country skiing biomechanics. He is Associate Professor at the University of Salzburg, Austria since 2010. Research field is biomechanics, sports engineering, training and testing in Wintersports.

\section{Yves C. Vanlandewijck:}

Yves C. Vanlandewijck is Professor in Rehabilitation Sciences at the Faculty of Kinesiology and Rehabilitation Sciences of the University of Leuven. His research interests include exercise physiology, biomechanics and ergonomics, applied to locomotor disabled in a rehabilitation to elite sports continuum. His main research applications focus on the 
development of evidence-based classification systems in disability sports to ensure fairness in athletic competition categories, with a particular interest in the relationship between intellectual functioning and performance of athletes with intellectual disability. From 1997 to 2001 he was the vice-president of the International Federation of Adapted Physical Activity; he is the founding editor of the European Journal of Adapted Physical Activity and the editor of the IOC Series Book "The Paralympic Athlete". He was a member of the IOC Medical and Scientific Working Group and member of the Associations Board of the International Council of Sport Science and Physical Education. He is a member of the Sport Science Committee of the International Paralympic Committee (IPC) since 1995 and Chairperson since 2004.

\section{Vesa Linnamo:}

Vesa Linnamo received his Ph.D. in Biomechanics from the University of Jyväskylä, Finland in 2002. His research interests involve motor control and neuromuscular adaptation along with sports biomechanics, especially in Nordic winter sports. He is currently working in the Department of Biology of Physical Activity, Faculty of Sport and Health Sciences, University of Jyväskylä as a professor in sports technology in Vuokatti, Finland. 


\section{Valeria Rosso:}

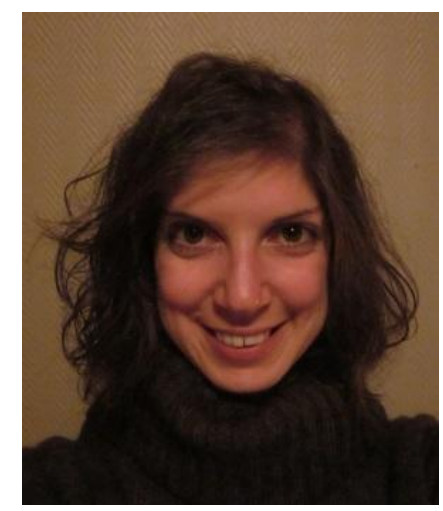

\section{Laura Gastaldi:}

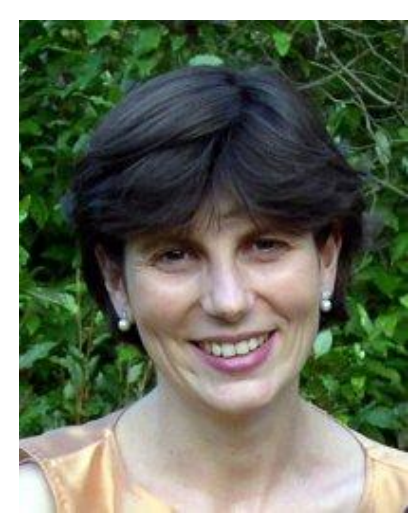

Walter Rapp:

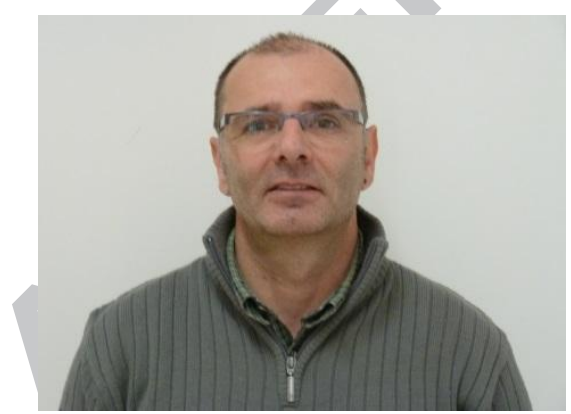


Stefan J. Lindinger:

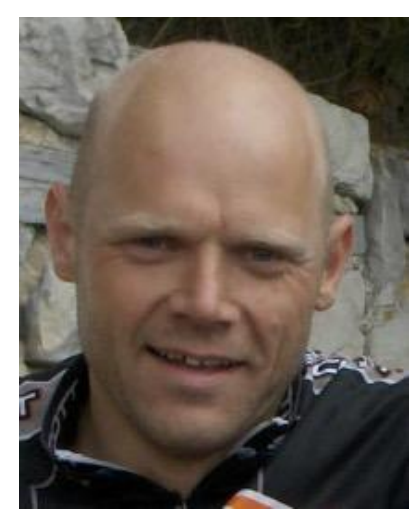

Yves C. Vanlandewijck:

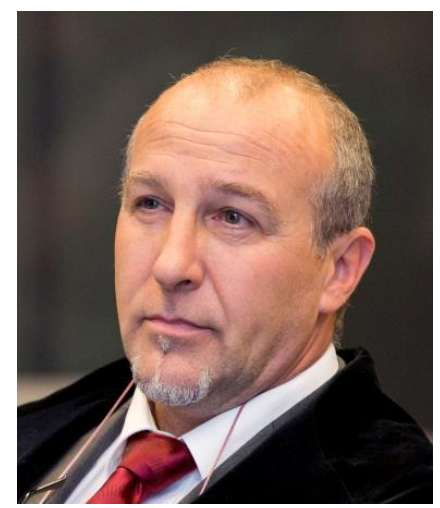

\section{Vesa Linnamo:}

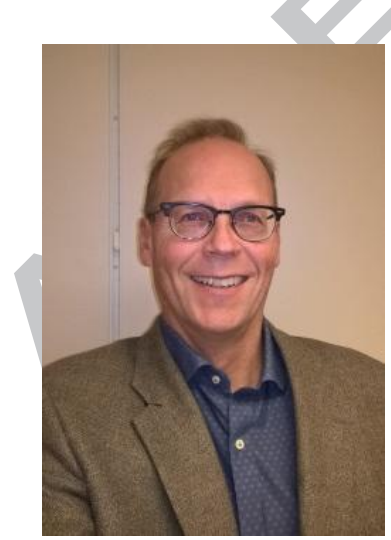

